\title{
BMJ Open Healthy living practices in families and child health: 5-year follow-up of Taiwan Birth Cohort Study
}

\author{
Yi-Ching Lin (D) , ${ }^{1}$ Yi-Fan Li, ${ }^{2}$ Tung-liang Chiang ${ }^{3}$
}

To cite: Lin Y-C, Li Y-F, Chiang T. Healthy living practices in families and child health: 5-year follow-up of Taiwan Birth Cohort Study. BMJ Open 2020;10:e033613. doi:10.1136/ bmjopen-2019-033613

- Prepublication history for this paper is available online. To view these files, please visit the journal online (http://dx.doi. org/10.1136/bmjopen-2019033613).

Received 04 September 2019 Revised 12 April 2020 Accepted 14 May 2020
Check for updates

(C) Author(s) (or their employer(s)) 2020. Re-use permitted under CC BY-NC. No commercial re-use. See rights and permissions. Published by BMJ.

${ }^{1}$ Department of Early Childhood and Family Education, National Taipei University of Education, Taipei, Taiwan

${ }^{2}$ Division of Clinical Chinese Medicine, National Research Institute of Chinese Medicine, Taipei, Taiwan

${ }^{3}$ Institute of Health Policy and Management, College of Public Health, National Taiwan University, Taipei, Taiwan

Correspondence to

Dr Yi-Fan Li;

yifanli@nricm.edu.tw

\section{ABSTRACT}

Objectives We have previously developed the Child Healthy Living Practices in Family (CHLPF) Index and found that the CHLPF Index was concurrently associated with the health of children at age 3. In this follow-up study, we aimed to examine whether healthy living practices in family at age 3 predicted health of children at school age. Design and setting Data came from the Taiwan Birth Cohort Study designed to assess the development and health of 24200 children born in 2005.

Participants A total of 18553 cohort members whose mothers or primary caregivers had completed 6-month, 3year, 5-year and 8-year surveys were included for analysis, representing a response rate of $87.3 \%$.

Outcome measures A multiple logistic regression model was used to test the relationship between mother-rated children's health at age 8 and the CHLPF Index level, after controlling for sex, birth outcomes, family structure, parental education, residential area, family income and mother-rated child's health at age 3 .

Results The percentage of mother-rated good health at age 8 was $79.7 \%$. Compared with the low CHLPF level, the adjusted $\mathrm{OR}$ of mother-rated good health was 1.38 (95\% Cl 1.19 to 1.60), 1.21 (95\% Cl 1.10 to 1.35) and 1.17 (95\% Cl 1.07 to 1.29), respectively, for high, high-low and mid-low CHLPF levels. Moreover, the prevalence of mother-rated good health at age 8 with high-level CHLPF Index in the low-income group was similar to that of the high-income group (83.72\% vs $84.18 \%$ ); the prevalence with low-level CHLPF Index in the low-income group was much lower than that of the high-income group $(70.21 \%$ vs $78.98 \%$ ).

Conclusions Our study underscores that high level of healthy living practices in early childhood is positively associated with good health at school age, particularly for children from disadvantaged families.

\section{INTRODUCTION}

Health promotion refers to helping people increase control over their health by developing their capacity for healthy living. ${ }^{1}$ From a socioecological perspective focused on the interrelations between organisms and their environments, health promotion shapes health habits to help improve people's health and well-being, ${ }^{2-4}$ which can be applied through different aspects like families, communities, social welfare, healthcare and

\section{Strengths and limitations of this study}

This study used the data set from the Taiwan Birth Cohort Study, which was the first large-scale, nationally representative and longitudinal study on a whole-year birth cohort in Taiwan.

- There is little panel data to investigate the association between preschool healthy living practices and mother-rated good health at school age.

- Mother-rated or primary caregiver-rated child health and living practices, which might be subjected to social desirability and cause potential reporting bias.

- The influence of real-life changes in the participating families through the 5 -year interval was not investigated in the present study.

health policy as a more comprehensive and integrative child health support to improve child and family well-being. ${ }^{5}$ Most centrally, family is the core base for children to promote their healthy life.

For children, the family is a major socialiser that forms an important proximal environment for developing routines, capacity, knowledge and norms for healthy living. ${ }^{6-8}$ If begun in early childhood, these familial factors can, in response to risks and adversities, promote positive health outcomes and reduce negative outcomes for children. ${ }^{9}$ Because family is involved in daily health promotion for children, ${ }^{10}$ the family context and its embedded routines are essential for shaping children's health, health behaviour and lifestyles during growth. ${ }^{11-13}$

The relationships between healthy lifestyles and child health outcomes are complex and multidimensional, and the relationship between healthy lifestyles and general health appears to be the most important. ${ }^{14}$ Daily family routines provide incremental benefits for children's general health, particularly to children growing up poor. ${ }^{7}$ Three-year-old children raised in poor families that practice healthy lifestyles including multiple healthpromoting behaviours have better general 
health outcomes and lower risks of developing health problems than do children raised in poor families that do not follow such practices. ${ }^{15}$ The cumulative effect of a series of child healthy living practices in family (CHLPF) is associated with the individual effect of singular health behaviour. ${ }^{716}$ Health-promoting behaviours might also explain the within-group variation in the health of children in poor families.

Policy analyses claim that healthy family practices in early childhood continue to positively affect children's health. ${ }^{14}$ If this claim is confirmed, it should be used as the basis for developing and strengthening children's long-term health. However, most of the existing literature used cross-sectional designs that demonstrated the association of CHLPF with health outcomes at a specific point in time. ${ }^{16}$ Thus, a longitudinal follow-up study that would investigate the associations between major variables ${ }^{6}$ is warranted to examine the long-term implications of these practices.

Therefore, building on the literature review ${ }^{5}$ and our previous study, ${ }^{15}$ we hypothesised that early development of CHLPF before age 3 leads to positive effects on health outcomes later on. In the current study, we aimed to examine whether CHLPF at age 3 predicted the health of children at school age.

\section{METHODS}

\section{Study design and setting}

This study was based on the Taiwan Birth Cohort Study (TBCS), which is the first large-scale and longitudinal study in Taiwan. TBCS used face-to-face interview questionnaires with mothers or primary caregivers to collect information on children's physical health, development, lifestyle, parenting and social and physical environment factors, to elucidate children's health profile and examine early origins of adult health based on the lifecourse perspective. In the present study, we hypothesised that early development of CHLPF before age 3 leads to positive effects on the health of children at age 8 .

\section{Participants}

The nationally representative cohort of 24200 eligible infants born in 2005 was initially taken from 206741 live births based on the National Birth Report Database using two-stage stratified random sampling. First, 369 townships were identified as primary sampling units (PSUs) and were stratified into 12 levels according to their urbanisation and total fertility rate. Second, individuals were sampled from 85 PSUs, and the samples were determined by probability proportionate to size. The sampling rate was approximately $11.7 \%$.

Among eligible children, mothers of 21248 (87.8\%) completed the baseline survey when the child was 6 months old and the children were recruited as cohort members. Subsequently, four waves of follow-up surveys were carried out at 18 months, 3 years, 5 years and 8 years of age, with response rates of $94.9 \%, 93.7 \%, 92.8 \%$ and
$91.9 \%$, respectively. For each wave of survey, face-to-face interviews were conducted after the mother or primary caregiver provided informed consent. A total of 18553 children with completed 6-month, 3-year, 5-year and 8-year surveys were included for analysis, representing a response rate of $87.3 \%$ (18 553/21 248).

\section{Variables}

\section{Independent variable: CHLPF Index}

This index was developed to evaluate the degree of a 3-year old's CHLPF, which was comprised of five elements: whether (1) vegetables and fruits are eaten daily, (2) physical activities are practiced daily, (3) hands are washed before meals and after using the bathroom, (4) television-viewing is less than 2 hours per day and (5) the child is exposed to secondhand smoke at home. ${ }^{15}$ All five elements were stratified into low (score $\leq 1$ ), midlow (score $=2$ ), mid-high (score $=3$ ) and high ( score $\geq 4$ ) CHLPF levels. Data of 3-year olds were used because studies have indicated that some forms of adolescent or adult behaviours could be tracked and observed in the third year of life. ${ }^{17-19}$

The five elements in the CHLPF Index were first chosen based on the previous literature that substantiated that these five elements are highly associated with children's health and also imply the level of a family's adoption of approaches that can enhance children's health and prevent diseases. ${ }^{15}$ Subsequently, the CHLPF Index has been validated through exploratory factor analysis (EFA) and confirmative factor analysis (CFA) ${ }^{15}$ The results of EFA indicated that CHLPF Index explained 28.21\% of the total variance. The goodness-of-fit indicators of CFA showed a good model fit (root mean square error of approximation $=0.025$, Comparative Fit Index $=0.967$, Normed Fit Index $=0.965, \chi^{2}$ by $\mathrm{df}=13.27$ ).

\section{Dependent variable: children's mother-rated health at age 8}

To measure children's health at age 8 , mothers or primary caregivers were asked 'How would you rate your child's health status on the whole?' The response was rated on a 5-point scale: very good, good, fair, poor and very poor. This variable was recoded as good health (' 1 ' for 'very good' and 'good') and as non-good health ('0' for 'fair', 'poor' and 'very poor').

\section{Covariates}

Sociodemographic characteristics are associated with health. ${ }^{19-22}$ Therefore, demographic characteristics (child's sex), children's birth outcomes (birth weight and gestational age) and parents' socioeconomic status before age 3 (family structure, family income, maternal education, paternal education and residential area) were included in the advanced analysis.

\section{Data analysis}

First, a Pearson's $\chi^{2}$ test was used to examine the association of the prevalence of mother-rated good health at age 8 with CHLPF Index and other covariates. Subsequently, a multiple logistic regression model was used to test the 
Table 1 Distribution of total participants and mother-rated good health at age of 8 for children across sociodemographic factors and CHLPF

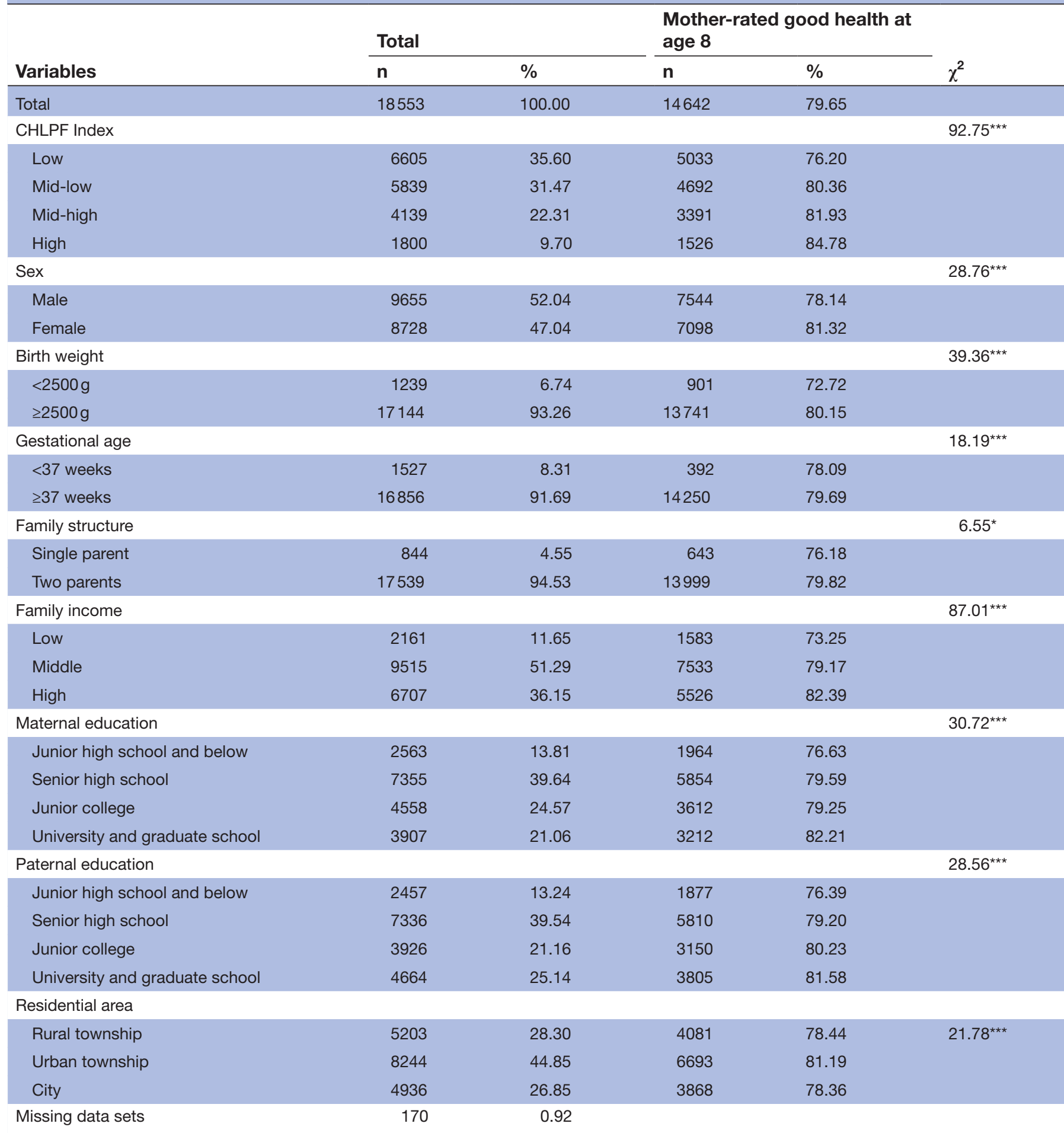

${ }^{*} \mathrm{p}<0.05 ;{ }^{* *} \mathrm{p}<0.01 ;{ }^{* * *} \mathrm{p}<0.001$.

CHLPF, Child Healthy Living Practices in Family.

relationships between CHLPF levels and health at age 8, after controlling for sex, family structure, family income, maternal education, paternal education, residential area and mother-rated child's health at age 3. Finally, a stratified analysis was presented the prevalence of motherrated good heath by the CHLPF Index and family income level at ages 8 and 3, respectively. The software SAS V.9.4 was used for all analyses in the current study.

\section{Patient and public involvement statement}

The TBCS employed four strategies to promote patient and public involvement. First, the principal investigator, 
Open access

Table 2 Crude and adjusted ORs of mother-rated health at children's age of 8 across sociodemographic factors and CHLPF

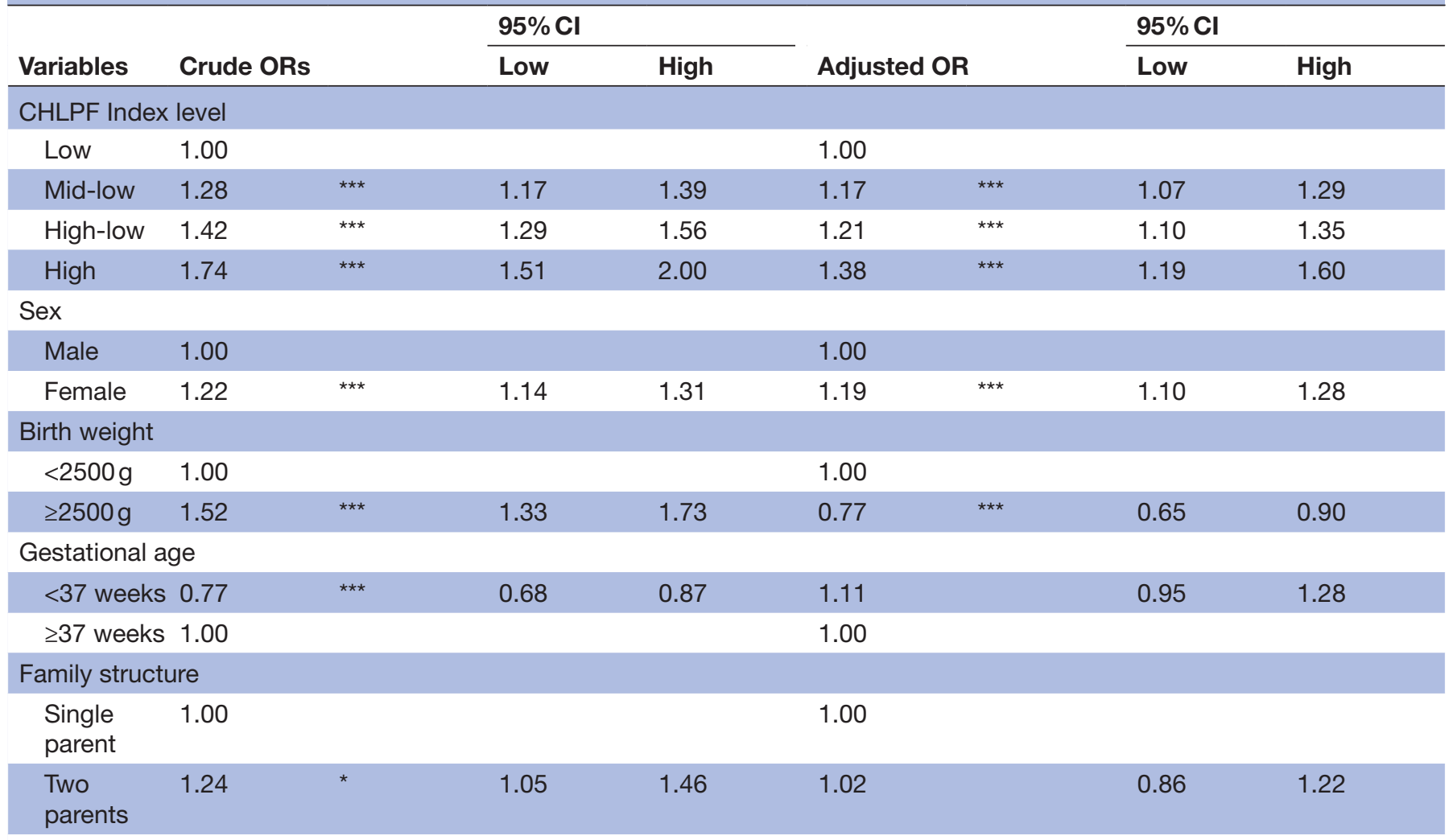

Family income

\begin{tabular}{|c|c|c|c|c|c|c|c|c|}
\hline Low & 1.00 & & & & 1.00 & & & \\
\hline Middle & 1.39 & $\star \star \star ~$ & 1.25 & 1.55 & 1.27 & 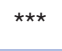 & 1.13 & 1.43 \\
\hline High & 1.71 & $\star \star \star$ & 1.53 & 1.92 & 1.47 & $\star \star \star \star ~$ & 1.28 & 1.69 \\
\hline $\begin{array}{l}\text { Junior high } \\
\text { school and } \\
\text { below }\end{array}$ & 1.00 & & & & 1.00 & & & \\
\hline $\begin{array}{l}\text { Junior } \\
\text { college }\end{array}$ & 1.17 & * & 1.04 & 1.31 & 1.01 & & 0.88 & 1.17 \\
\hline $\begin{array}{l}\text { University } \\
\text { and } \\
\text { graduate } \\
\text { school }\end{array}$ & 1.41 & $\star \star \star \star ~$ & 1.25 & 1.59 & 1.15 & & 0.97 & 1.36 \\
\hline \multicolumn{9}{|c|}{ Paternal education } \\
\hline $\begin{array}{l}\text { Junior high } \\
\text { school and } \\
\text { below }\end{array}$ & 1.00 & & & & 1.00 & & & \\
\hline $\begin{array}{l}\text { Senior } \\
\text { high } \\
\text { school }\end{array}$ & 1.18 & $\star \star$ & 1.06 & 1.31 & 1.06 & & 0.94 & 1.20 \\
\hline $\begin{array}{l}\text { Junior } \\
\text { college }\end{array}$ & 1.25 & $\star \star \star *$ & 1.11 & 1.42 & 1.06 & & 0.91 & 1.22 \\
\hline
\end{tabular}


Table 2 Continued

\begin{tabular}{|c|c|c|c|c|c|c|c|}
\hline \multirow[b]{2}{*}{ Variables } & \multirow[b]{2}{*}{ Crude ORs } & & \multicolumn{2}{|c|}{$95 \% \mathrm{Cl}$} & \multirow[b]{2}{*}{ Adjusted OR } & \multicolumn{2}{|c|}{$95 \% \mathrm{Cl}$} \\
\hline & & & Low & High & & Low & High \\
\hline $\begin{array}{l}\text { University } \\
\text { and } \\
\text { graduate } \\
\text { school }\end{array}$ & 1.37 & $\star \star \star *$ & 1.22 & 1.54 & 1.05 & 0.90 & 1.24 \\
\hline
\end{tabular}

Residential area

\begin{tabular}{|c|c|c|c|c|c|c|c|c|}
\hline $\begin{array}{l}\text { Rural } \\
\text { township }\end{array}$ & 1.00 & & & & 1.00 & & & \\
\hline $\begin{array}{l}\text { Urban } \\
\text { township }\end{array}$ & 1.18 & *** & 1.08 & 1.29 & 1.10 & * & 1.00 & 1.20 \\
\hline City & 0.99 & & 0.91 & 1.09 & 0.91 & & 0.82 & 1.00 \\
\hline \multicolumn{9}{|c|}{ Mother-rated health of 3-year olds } \\
\hline $\begin{array}{l}\text { Good } \\
\text { health }\end{array}$ & 3.49 & *** & 3.23 & 3.77 & 3.36 & 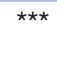 & 3.11 & 3.63 \\
\hline
\end{tabular}

${ }^{*} \mathrm{p}<0.05 ;{ }^{* *} \mathrm{p}<0.01 ;{ }^{* * *} \mathrm{p}<0.001$.

CHLPF, Child Healthy Living Practices in Family.

coprincipal investigators and staff from the Health Promotion Administration worked together to develop the conceptual framework and study plans according to the objectives of TBCS. Second, for each wave of survey, the questionnaire was constructed with reference to previous research and social contexts. Third, at the pretest and pilot study, participants' comments and feedback were further collected to revise the questionnaires. Fourth, the TBCS results were disseminated to the participants through newsletters, monographs, research publications and public symposia or conferences. However, participants were not directly involved in the recruitment to and conduct of the study.

\section{RESULTS}

The study population comprised 18553 8-year-old children (boys: $52.0 \%$ and girls: $47.0 \%$ ) (table 1). The majority of children had birth weight more than $2500 \mathrm{~g}$ $(93.3 \%)$ and gestational age more than 37 weeks (91.7\%). Most of them lived with two parents $(94.5 \%)$, came from middle-income families $(51.3 \%)$, and almost half of their mothers had completed at least college education (45.6\%). Regarding CHLPF Index, low-level children accounted for about one-third $(35.6 \%)$, followed by midlow level $(31.5 \%)$, mid-high level $(22.3 \%)$ and high level $(9.7 \%)$.

The prevalence of mother-rated good health for girls $(81.3 \%)$ was significantly higher than that for boys $(78.1 \%) \quad\left(\chi^{2}=28.76, p<0.0001\right) \quad($ table 1$)$. Significantly more children who lived with two parents $(79.8 \%)$ had mother-rated good health than did children who lived with a single parent $(76.2 \%)\left(\chi^{2}=6.55, \mathrm{p}=0.01\right)$. There were socioeconomic differentials in mother-rated health.
The prevalence of mother-rated good health was higher among children from high-income families $(82.4 \%)$ compared with children from middle-income $(79.2 \%)$ and low-income $(73.3 \%)$ families $\left(\chi^{2}=87.0, \mathrm{p}<0.0001\right)$. Moreover, significantly more children whose parents had graduated from junior college or university had mother-rated good health than did those whose parents had graduated from senior high school or below. Finally, significantly more children with a high CHLPF Index level had mother-rated good health than did those with a lower CHLPF Index level $\left(\chi^{2}=92.75, p<0.0001\right)$.

A multiple logistic regression model showed that a child's CHLPF Index level was a significant predictor of mother-rated good health, after it had been adjusted for sex, birth outcomes, family structure, family income, parental education, residential area and the motherrated health of 3-year olds (table 2). More specifically, the OR of mother-rated good health was 1.4 (adjusted OR $(\mathrm{AOR})=1.38,95 \%$ CI 1.19 to 1.60$), 1.2(\mathrm{AOR}=1.21$, 95\% CI 1.10 to 1.35$)$ and $1.2(\mathrm{AOR}=1.17,95 \%$ CI 1.07 to 1.29) higher, respectively, for children with a high, high-low and mid-low CHLPF Index level than for their lowest counterparts.

Table 3 presents the prevalence of mother-rated good health at ages 8 and 3, stratified by CHLPF Index levels and family income. The prevalence of mother-rated good health at age 8 was observed with a significant CHLPF Index upwards gradient across all family income levels. Importantly, when children had high-level CHLPF Index in the low-income group, the prevalence of mother-rated good health at age 8 was similar to the high-income group $(83.72 \%$, $95 \%$ CI $76.20 \%$ to $89.63 \%$ vs $84.18 \%$, $95 \%$ CI $81.61 \%$ to $86.51 \%$, absolute difference $=0.46 \%$ ). 


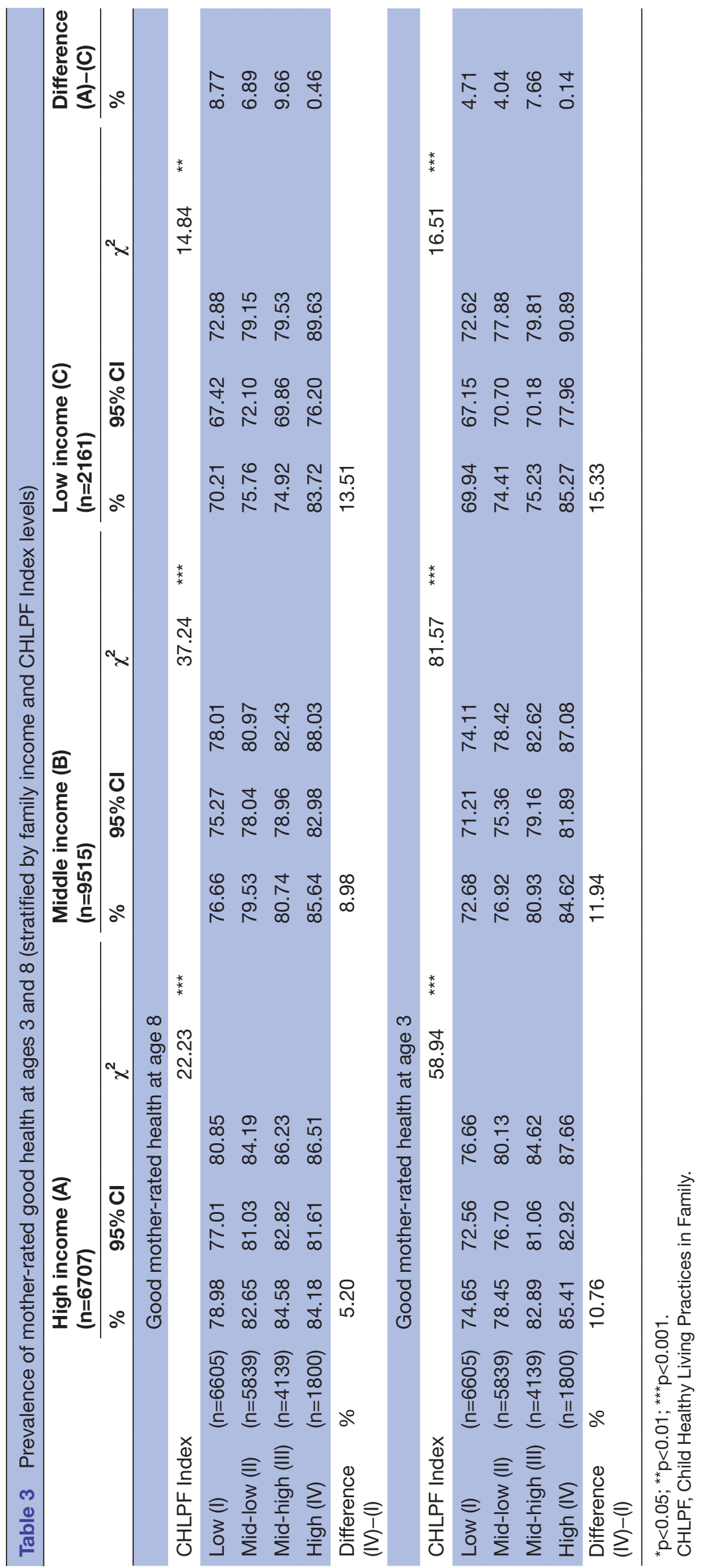

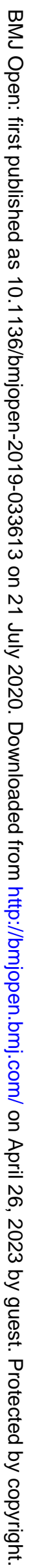


However, while children had low-level CHLPF Index in the low-income group, the prevalence of mother-rated good health was much lower than that of the high-income group $(70.21 \%, 95 \%$ CI $67.42 \%$ to $72.88 \%$ vs $78.98 \%$, $95 \%$ CI $77.01 \%$ to $80.85 \%$, absolute difference $=8.77 \%$ ). The CHLPF Index gradients consistently remained similar across all income levels, and the absolute difference at age 8 was more evident as the income level declined $(5.20 \%$ in high-income level vs $13.51 \%$ in low-income level). The pattern of age 3 was similar to that of age 8 .

\section{DISCUSSION}

The current study found that high levels of CHLPF Index at age 3 were significantly associated with mother-rated good health at age 8 , using data from the nationally representative birth cohort study in Taiwan. Moreover, this study found that the low-income group with high CHLPF Index levels had a much higher prevalence of mother-rated good health than the high-income group with low CHLPF Index levels, for children at age 8 as well as at age 3 .

Our findings were consistent with the literature that healthy living practices promote health in general. ${ }^{10} 1523$ More importantly, our study found that the association between CHLPF and children's health was sustained over time. The findings of long-term effect support that the environment in which children are raised establishes a solid foundation for their future health. ${ }^{10}$ Therefore, a feasible approach to ensure children's future health is to encourage parents and families to establish healthy practices or habits with their children. ${ }^{24}$ For example, restricting both child and parental television-viewing time early on would decrease television exposure. ${ }^{25}$

This study also identified that the association between CHLPF and children's health was sustained and remained stronger in the low-income families. Particularly, we observed that children with good healthy living practices in low-income families would be healthier than children with poor healthy living practices in highincome families. Therefore, we suggest that healthy living practices in families are crucial for enhancing child health, especially for children with socioeconomic disadvantages.

Moreover, the discrepancy in the prevalence of mother-rated good health between high-income and low-income groups increased across all CHLPF Index levels as children grew up (eg, low-CHLPF Index level: $4.71 \%$ at age 3 vs $8.77 \%$ at age 8 ). Therefore, making the effort to follow through basic health routines as part of CHLPF early in the child's life could compensate the impact of health disparity.

This study had some limitations. First, all measures of child health and elements of CHLPF Index were provided by parents; therefore, these responses are subjected to social desirability causing potential reporting bias. We also believe that information on parents' actual behaviours would be a more direct path to speculate the behaviours of young children. However, the TBCS collected limited data on parental health behaviours. Second, through the 5-year interval, the actual changes in the participating families such as financial status or marital status changes were not taken into account and investigated. The impact of such changes on CHLPF may have been overlooked.

Despite these limitations, the findings of this study contribute to the literature regarding healthy living practices in families and its association with children's longterm health and health equality.

\section{CONCLUSIONS}

Our study underscores that high level of healthy living practices in early childhood is positively associated with good health at school age, particularly for children from disadvantaged families. Therefore, we suggest that public policies should pay more attention to early intervention on familial healthy living practice in order to promote children's health.

Acknowledgements This study is based on the data from the Taiwan Birth Cohort Study, of which T-IC is the primary investigator. We gratefully acknowledge the financial and administrative support from the Health Promotion Administration, Ministry of Health and Welfare, and the time and continuing support from the participating families of the Taiwan Birth Cohort Study. We thank Professor Chuhsing Kate Hsiao for her advice regarding the statistical analyses and interpretation of data. We also thank the National Research Institute of Chinese Medicine for supporting the Article Processing Charge.

Contributors $\mathrm{Y}$-CL designed and executed the study, interpreted the data and drafted and revised the manuscript. Y-FL collaborated with the design, conducted the data analyses and collaborated in writing of the manuscript. T-IC designed and executed the study and collaborated in writing of the manuscript. All authors approved the final manuscript as submitted and agree to be accountable for all aspects of the work.

Funding This work was supported by grants from the Health Promotion Administration, Ministry of Health and Welfare, Republic of China (BHP-PHRC-92-4, D0H93-HP-1702, DOH94-HP- 1802, DOH95-HP-1802, DOH96-HP-1702, DOH99-HP-1702, MOHW103-HPA-H-114-1 23 706).

Competing interests None declared.

Patient consent for publication Not required.

Ethics approval All procedures performed in this study involving human participants were in accordance with the ethical standards of National Taiwan University Hospital Research Ethics Committee (approval number 1073703519) and with the 1964 Helsinki declaration and its later amendments or comparable ethical standards. Informed consent was obtained from all individual participants included in the study.

Provenance and peer review Not commissioned; externally peer reviewed.

Data availability statement Data are available upon reasonable request. The datasets generated and analysed during the current study are not publicly available owing to the terms of consent to which the participants agreed, but data are available upon reasonable request and with permission of the Health Promotion Administration at the Ministry of Health and Welfare in Taiwan.

Open access This is an open access article distributed in accordance with the Creative Commons Attribution Non Commercial (CC BY-NC 4.0) license, which permits others to distribute, remix, adapt, build upon this work non-commercially, and license their derivative works on different terms, provided the original work is properly cited, appropriate credit is given, any changes made indicated, and the use is non-commercial. See: http://creativecommons.org/licenses/by-nc/4.0/.

ORCID iD

Yi-Ching Lin http://orcid.org/0000-0002-6835-7116 


\section{REFERENCES}

1 World Health Organisation. Ottawa Charter for Health Promotion: First International Conference on Health Promotion Ottawa, 1986. Available: https://www.healthpromotion.org.au/images/ottawa charter_hp.pdf [Accessed 12 Nov 2018].

2 Sallis JF, Cervero RB, Ascher W, et al. An ecological approach to creating active living communities. Annu Rev Public Health 2006;27:297-322.

3 Stokols D. Establishing and maintaining healthy environments. toward a social ecology of health promotion. Am Psychol 1992;47:6-22.

4 Yoo J, Slack KS, Holl JL. The impact of health-promoting behaviors on low-income children's health: a risk and resilience perspective. Health Soc Work 2010;35:133-43.

5 Perrin JM, Boat TF, Kelleher KJ. The influence of health care policies on children's health and development. SRCD 2016;29.

6 Lin YC, Seo DC. Cumulative family risks across income levels predict deterioration of children's general health during childhood and adolescence. PLoS One 2017;12:e0177531.

7 Poutanen R, Lahti S, Tolvanen M, et al. Parental influence on children's oral health-related behavior. Acta Odontol Scand 2006;64:286-92.

8 UNICEF. Child poverty in perspective: an overview of child wellbeing in rich countries, 2007. Available: https://www.unicef-irc.org/ publications/pdf/rc7_eng.pdf [Accessed 12 Nov 2018].

9 Masten AS, Risk GN. vulnerability, and protective factors in developmental psychopathology. In: Lahey BB, Kazdin AE, eds. Advances in clinical child psychology. Boston, MA: Springer, 1985: 1-52.

10 Christensen P. The health-promoting family: a conceptual framework for future research. Soc Sci Med 2004;59:377-87.

11 World Health Organisation Regional Office for Europe. Young people's health in context : Health Behaviour in School-aged Children (HBSC) study: international report from the 2001/2002 Survey, 2004. https://apps.who.int/iris/handle/10665/107560

12 Allen FM, Warner M. A developmental model of health and nursing. $J$ Fam Nurs 2002;8:96-135.
13 Izenstark D, Oswald RF, Holman EG, et al. Rural, low-income mothers' use of family-based nature activities to promote family health. J Leisure Res 2016;48:134-55.

14 Mollborn S, James-Hawkins L, Lawrence E, et al. Health lifestyles in early childhood. J Health Soc Behav 2014;55:386-402.

15 Lin YC, Wu JCL, Chiou ST, et al. Erratum to: healthy living practices in families and child health in Taiwan. Int J Public Health 2016;61:391-3.

16 Bauman LJ, Silver EJ, Stein REK. Cumulative social disadvantage and child health. Pediatrics 2006;117:1321-8.

17 Caspi A, Moffitt TE, Newman DL, et al. Behavioral observations at age 3 years predict adult psychiatric disorders. longitudinal evidence from a birth cohort. Arch Gen Psychiatry 1996;53:1033-9.

18 Caspi A, Harrington H, Milne B, et al. Children's behavioral styles at age 3 are linked to their adult personality traits at age 26 . $J$ Pers 2003;71:495-514.

19 Marmot M. Commission on social determinants of health. achieving health equity: from root causes to fair outcomes. The Lancet 2007;370:1153-63

20 Marmot M, Friel S, Bell R, et al. Commission on social determinants of health. closing the gap in a generation: health equity through action on the social determinants of health. The Lancet 2008;372:1661-9.

21 Currie C, Zanotti C, Morgan A, et al. Social determinants of health and well-being among young people. Health Behaviour in Schoolaged Children (HBSC) study: international report from the 2009/2010 survey, 2009: 1-271.

22 Brotman LM, Dawson-McClure S, Huang K-Y, et al. Early childhood family intervention and long-term obesity prevention among high-risk minority youth. Pediatrics 2012;129:e621-8.

23 World Health Organization. Healthy setting, 2015. Available: http:// www.who.int/healthy_settings/en/ [Accessed 15 Mar 2020].

24 Baker S, Morawska A, Mitchell AE. Do Australian children carry out recommended preventive child health behaviours? insights from an online parent survey. J Paediatr Child Health 2020;56:900-7.

25 Chiu YC, Li YF, Wu WC, et al. The amount of television that infants and their parents watched influenced children's viewing habits when they got older. Acta Paediatr 2017;106:984-90 